University of Nebraska - Lincoln

DigitalCommons@University of Nebraska - Lincoln

US Army Research

U.S. Department of Defense

2010

Shrapnel-Induced Mandibular Hypomobility

David E. Palo

Teampalosb@aol.com

Paul J. Warden

Follow this and additional works at: https://digitalcommons.unl.edu/usarmyresearch

Part of the Operations Research, Systems Engineering and Industrial Engineering Commons

Palo, David E. and Warden, Paul J., "Shrapnel-Induced Mandibular Hypomobility" (2010). US Army

Research. 142.

https://digitalcommons.unl.edu/usarmyresearch/142

This Article is brought to you for free and open access by the U.S. Department of Defense at DigitalCommons@University of Nebraska - Lincoln. It has been accepted for inclusion in US Army Research by an authorized administrator of DigitalCommons@University of Nebraska - Lincoln. 


\title{
Shrapnel-Induced Mandibular Hypomobility
}

\author{
David E. Palo, DDS, * and Paul J. Warden, DDS, MD†
}

\begin{abstract}
Mandibular hypomobility can develop from direct injury to, or as a result of disorders affecting, the supporting structures of the temporomandibular joint. This can be subdivided into intra-articular and extraarticular processes. Ankylosis is commonly associated with trauma (31\% to $98 \%$ ), followed by infections (10\% to $49 \%)$ and systemic disease (10\%). ${ }^{1}$ Temporomandibular joint ankylosis is an intra-articular process characterized by fibrous, fibro-osseous, or osseous obliteration of the joint space. ${ }^{2}$ Pseudoankylosis involves extracapsular causes of restricted jaw motion that include, but are not limited to, coronoid-zygomatic fusion, coronoid hypertrophy, and muscular fibrosis. ${ }^{2}$ Shrapnel injuries can be as devastating as high-velocity gunshot wounds, with functional and esthetic consequences, depending on the velocity, size, shape, and jagged edges of the fragments. ${ }^{3,4}$ Traumatic life support measures are paramount during the immediate postinjury setting. The airway and hemodynamic status must be maintained, because the oxygen-carrying capacity is essential for wound healing and the prevention of infection. ${ }^{3,4} \mathrm{~A}$ secure airway controlled with an endotracheal tube or tracheostomy needs early consideration because bleeding and edema can result in airway compromise. ${ }^{3,4}$ The
\end{abstract}

Received from the Department of Oral and Maxillofacial Surgery,

Womack Army Medical Center, Ft. Bragg, NC.

*Former Attending, Oral and Maxillofacial Surgeon, Major, US Armed Forces

†Former Attending, Oral and Maxillofacial Surgeon, Lieutenant, US Armed Forces.

The opinions or assertions contained herein are the private views of the authors and are not to be construed as official or as reflecting the views of the US Army Medical Department, Department of the Army, or Department of Defense.

The citation of commercial organizations and trade names in this report do not constitute an official Department of the Army or Department of Defense endorsement or approval of the products or services of these organizations.

Address correspondence and reprint requests to Dr Palo: 100 State Street, Suite B102, Erie, PA 16507; e-mail: Teampalodsb@ aol.com

(1) 2010 Published by Elsevier Inc on behalf of the American Association of

Oral and Maxillofacial Surgeons

0278-2391/10/6810-0046\$36.00/0

doi:10.1016/i.joms.2010.04.008 securing of the airway should be followed by a comprehensive examination of the patient to reveal additional injuries.

\section{Report of a Case}

The oral and maxillofacial surgery service was consulted by the orthopedic surgery department to evaluate a 23-yearold male US Army specialist from the 82nd Airborne Division (Fort Bragg, NC). He had sustained multiple facial and extremity shrapnel injuries while serving in Iraq during Operation Iraqi Freedom. On October 26, 2003, as Ramadan was beginning, his high-mobility multipurpose wheeled vehicle (HUMV) was destroyed by a roadside-improvised explosive device. He was 1 of 2 survivors of the 4 manning the vehicle. He was flown by medical evacuation helicopter to the 28th Combat Surgical Hospital in Baghdad, Iraq. His treatment included hemostasis, debridement of wounds, and closure of the facial lacerations. He arrived at Womack Army Medical Center on November 13, 2003, for definitive surgical care.

Clinically, the patient exhibited a $3-\mathrm{cm}$ entrance stellate scar on the left side of his face.

Remarkably, no facial nerve palsy or trigeminal nerve paresthesia was present. Pain on maximal opening was recorded as 4 to 6 of 10 on a visual analog scale. However, he exhibited trauma-related mandibular hypomobility with a maximal interincisal opening of $12 \mathrm{~mm}$. The lateral excursions were measured as $6 \mathrm{~mm}$ to the left and $3 \mathrm{~mm}$ to the right. Other injuries included large avulsive lacerations to the left forearm, hand, and right ankle. Computed tomography and plain film radiography revealed multiple, tiny, scattered shrapnel fragments, with a larger $2.0 \times 1.5-\mathrm{cm}$ shrapnel fragment located along the medial surface of the left condyle and comminution of the left coronoid process (Figs 1, 2).

On the basis of these imaging and clinical examination findings, it was concluded that the large shrapnel fragment at the left condyle was impinging on the condylar range of motion, because it was wedged anterior and medial to the condyle and temporal bone. Owing to the proximity of the fragment to the maxillary artery and pterygoid plexus and the reported history of brisk bleeding from the site at resuscitation, it was determined that wide access was necessary for potential management of hemorrhage. An extraoral approach, with a vertical ramus osteotomy for access, was planned.

The patient was taken to the operating room for combined oral and maxillofacial surgery and orthopedic surgery procedures, with awake fiberoptic intubation and general anesthesia. The examination under general anesthesia revealed no improvement of the maximal incisal opening (MIO) of $12 \mathrm{~mm}$. A left submandibular approach was used, with exposure of the lateral mandibular cortex and conservation of the periosteal blood supply. Rigid internal fixation, 


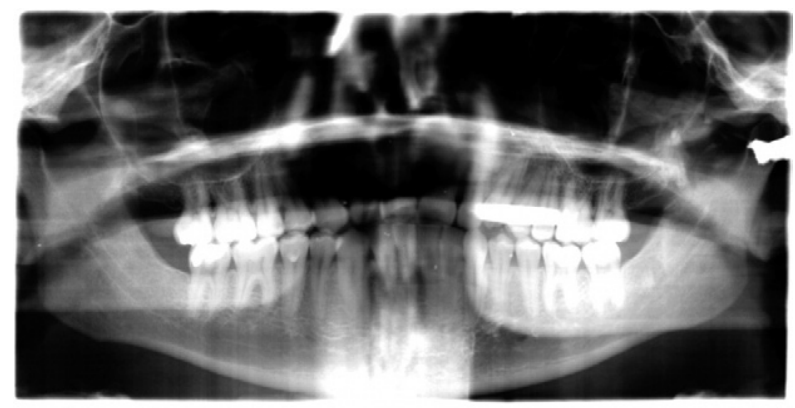

FIGURE 1. Preoperative panoramic radiograph showing $2.0 \times$ $1.5-\mathrm{cm}$ shrapnel fragment located at medial surface of left condyle and obliteration of left coronoid process.

Palo and Warden. Shrapnel-Induced Hypomobility. J Oral Maxillofac Surg 2010.

consisting of 2 Synthes $2.3-\mathrm{mm}$, 4-hole titanium miniplates (Synthes, Paoli, PA) (Fig 3), was adapted to the ramus, and screw holes were drilled before creation of the osteotomy to ensure precise repositioning of the osteotomized segments. ${ }^{6}$ A vertical ramus osteotomy was performed, and the proximal segment was distracted laterally and rotated superiorly to expose the medial ramus soft tissues. ${ }^{5-7}$ Optimal direct access to the foreign body was achieved. The shrapnel was carefully removed without incident, and hemostasis was maintained (Fig 4).

An MIO of $50 \mathrm{~mm}$ was achieved with brisement (ie, forceful manipulation of the jaw before the patient emerged from anesthesia). ${ }^{2}$ This was reproducible with finger pressure. No maxillomandibular fixation was deemed necessary. The patient recovered uneventfully without experiencing inferior alveolar or facial nerve injury or occlusal discrepancies.

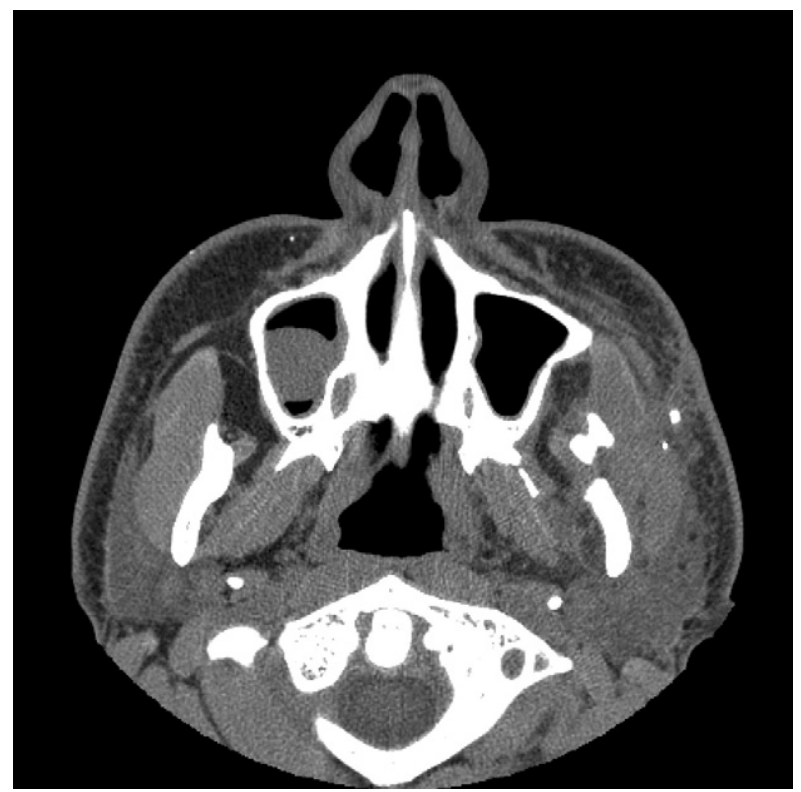

FIGURE 2. Axial computed tomography scan showing prominen portion of shrapnel along path of entrance located anterior to left ramus.

Palo and Warden. Shrapnel-Induced Hypomobility. J Oral Maxillofac Surg 2010.

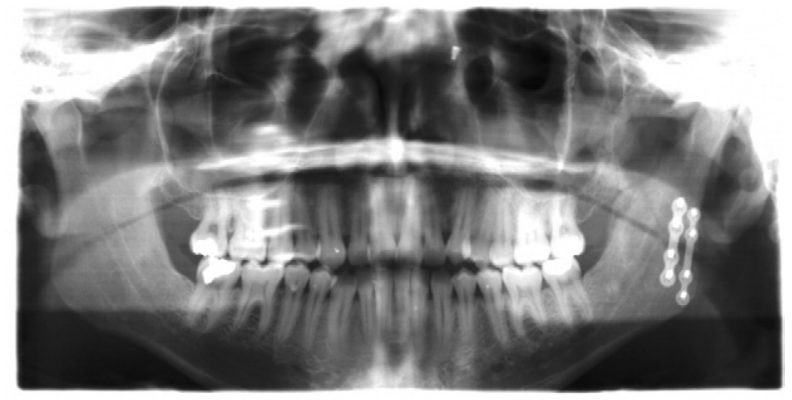

FIGURE 3. Postoperative panoramic radiograph showing 2 Synthes 4-hole miniplates and shrapnel removed.

Palo and Warden. Shrapnel-Induced Hypomobility. J Oral Maxillofac Surg 2010.

Postoperative physical therapy to maintain the maximal opening included immediate use of tongue depressors and the Therabite Jaw Motion Rehabilitation System (Therabite, Bryn Mawr, PA). The Therabite is a patient-driven device that provides intermittent passive motion and stretch exercises (Fig 5). Initially, the patient was given a stack of tongue blades and instructed to insert additional blades 5 to 7 times daily for at least 1 minute each time. Initially, he had difficulty using the tongue blades because of a postoperative splint on his left hand and forearm and required assistance to perform his physical therapy (MIO) range of motion exercises. After the Therabite was acquired, he was able to perform the range of motion exercises without difficulty. His postoperative course was uneventful, with a gradual MIO increase from 20 to $32 \mathrm{~mm}$. The lateral excursions improved slightly to $11 \mathrm{~mm}$ to left and $3 \mathrm{~mm}$ to right postoperatively. He was without pain on mastication and scored 4 of 10 on the visual analog scale during MIO.

Four months later, a repeat brisement procedure was performed immediately after induction of anesthesia for revision orthopedic surgery. An MIO of $48 \mathrm{~mm}$ was attained. At his last follow-up visit, the patient was able to open actively to $36 \mathrm{~mm}$ without masticatory pain or dysfunction.

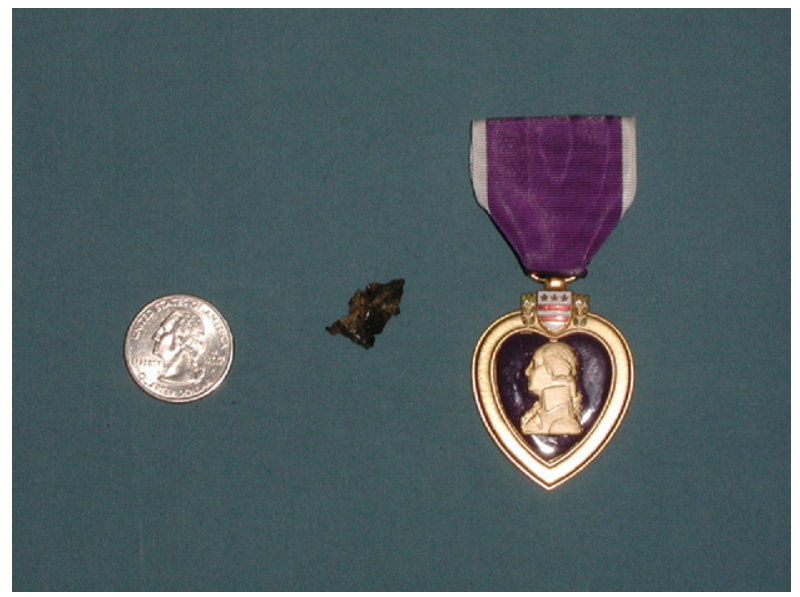

FIGURE 4. Shrapnel fragment $(2.0 \times 1.5 \mathrm{~cm})$ removed and positioned next to Purple Heart medal with US quarter for size representation.

Palo and Warden. Shrapnel-Induced Hypomobility. J Oral Maxillofac Surg 2010. 


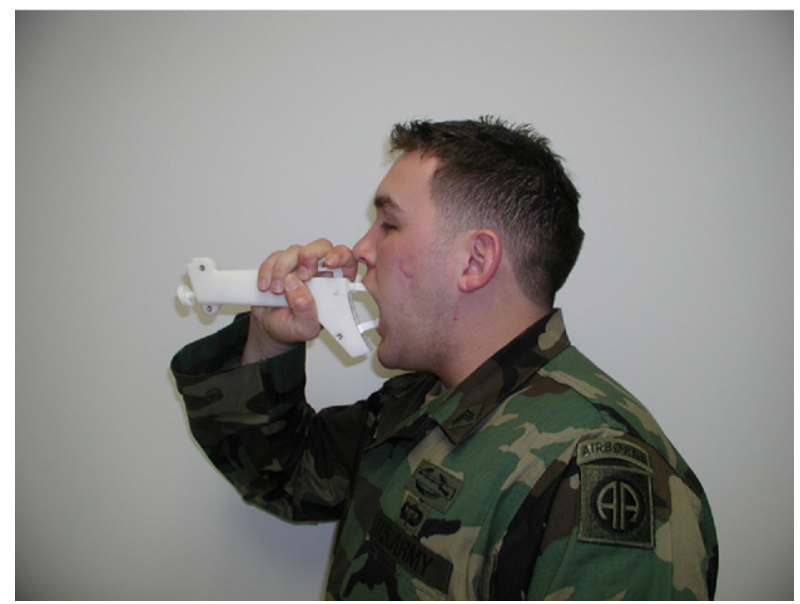

FIGURE 5. Patient using Therabite Jaw Motion Rehabilitation System.

Palo and Warden. Shrapnel-Induced Hypomobility. J Oral Maxillofac Surg 2010.

\section{Discussion}

This technique, as previously described by Larsen and Smead, ${ }^{6}$ provides excellent exposure to the tissues that lie medially between the angle of the mandible and the skull base, making it an ideal choice for this situation. The use of rigid internal fixation with adaptation of the miniplates before creation of the osteotomy was easily performed and made the need for maxillomandibular fixation unnecessary. This approach has little risk of inferior alveolar nerve injury, intraoral contamination, or changes in the occlusal relationship.

\section{References}

1. Kaban LB: A protocol for management of TMJ ankylosis. J Oral Maxillofac Surg 48:1145, 1990

2. American Association of Oral and Maxillofacial Surgeons: Parameters and Pathways: Clinical Practice Guidelines for Oral and Maxillofacial Surgery (AAOMS Para Path 01), Version 3.0. J Oral Maxillofac Surg 59: 2001 (suppl)

3. Montamedi MHK: Primary management of maxillofacial hard and soft tissue gunshot and shrapnel injuries. J Oral Maxillofac Surg 61:1390, 2003

4. Hollier L, Grantcharova EP, Kattash M: Facial gunshot wounds: A 4-year experience. J Oral Maxillofac Surg 59:277, 2001

5. Kenichi S, Tamura H, Watahiki R, et al: A surgical technique using vertical ramus osteotomy without detaching lateral pterygoid muscle for high condylar fractures. J Oral Maxillofac Surg 60:709, 2002

6. Larsen PE, Smead WL: Vertical ramus osteotomy for improved exposure of the distal internal carotid artery: A new technique. J Vasc Surg 15:226, 1992

7. Ariyan S, Saski C, Spencer D: Radical en bloc resection of the temporal bone. Am J Surg 142:443, 1981 